\title{
FABRICAÇÃO DE CONCRETO AUTOADENSÁVEL COM UTILIZAÇÃO DE RESÍDUOS DE MARMORARIAS COMO ADIÇÃO MINERAL
}

\section{Manufacturing self-compacting concrete with addition of waste fine marble}

\author{
Melquizedec Arcos RODRIGUES', João de Almeida MELO FILHO ${ }^{2}$
}

Recebido em 16 de dezembro de 2018; aceito em 18 de fevereiro de 2020; disponível on-line em 11 de maio de 2020.

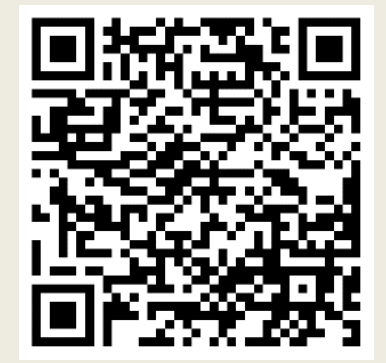

PALAVRAS CHAVE:

Resíduos sólidos de marmorarias;

Concreto autoadensável; Reciclagem;

Construção civil;

Reologia do CAA

\section{KEYWORDS:}

Solid waste marble shops; Self-compacting concrete; Recycling; Construction; Rheology of the SCC.

\section{* Contato com o autor:}

${ }^{1}$ e-mail: melkrodrigues@hotmail.com (M. A. Rodrigues)

Mestre em Engenharia Civil. Professor Assistente do Departamento de Engenharia Mecânica. Universidade Estadual do Amazonas - UEA.

2e-mail: jalmeida26179@gmail.com (J. A. Melo Filho)

Doutor em Engenharia Civil. Professor Adjunto da Faculdade de Tecnologia da Universidade Federal do Amazonas - UFAM. de mármores/granitos (RMG) das marmorarias na fabricação de concreto autoadensável (CAA). A metodologia adotada foi a realização de vários ensaios laboratoriais: de caracterização; das propriedades reológicas, mecânicas, físicas e químicas do CAA. Foram aplicados dois superplastificantes, sulfonado e polimérico. Os agregados foram caracterizados por ensaios de granulometria, massa específica; massa unitária em estado solto; e massa unitária em estado compactado. Os RMG foram submetidos a ensaio de massa específica e análise de Fluorescência de Raios X. Como ensaios reológicos foram realizados: Espalhamento, T500, Funil V e Caixa L; e Ensaios de Resistência à Compressão e à Flexão, Absorção, Índice de Vazios, Massa Específica e análise de Reação Álcali Agregado (RAA), no estado endurecido. Os resultados mostraram-se eficazes com até $30 \%$ de substituição do cimento por RMG. No estado fresco esse CAA atendeu aos requisitos da NBR 15823 (ABNT, 2010), se comportando como concreto adequado para utilização nas aplicações correntes. No estado endurecido apresentou resistência à compressão de $35 \mathrm{MPa}$ e resistência à flexão de 7,0 MPa, satisfazendo a NBR 15805 (ABNT, 2010), podendo também ser utilizado na produção de pavimentos de concreto e assim contribuindo para a redução de resíduos espalhados nas empresas, diminuição de danos ao meio ambiente e trazendo economia para a obtenção de CAA.

ABSTRACT: The objective of study is to determine the cement replacement percentage for waste marble / granite (WMG) of marble shops in the manufacture of self-compacting concrete (SCC). The methodology adopted was conducting several laboratory tests: characterization; of rheological, mechanical, physical and chemical SCC. Two superplasticizers were used, sulfonated and polymeric. The aggregates were characterized by granulometry test, specific mass; unitary mass loose state; and unit mass in compressed state. The WMG were subjected to density test and X-rays fluorescence analysis. As rheological tests were performed: slumpflow, slumpflow T500, funnel $V$ and L-box; and Testing of Compressive Strength and Flexion, Absorption, and Voids Index SCC Density in the hardened state, as well as tests on mortar bars to check Alkali Aggregate Reaction (AAR). The results were effective for most traits SCC, until 30\% replacement of cement with WMG. In this fresh SCC met the requirements of NBR 15823 (ABNT, 2010), behaving like proper concrete for use in most current applications. In the hardened state showed compression strength of $35 \mathrm{MPa}$ and bending strength of 7.0 MPa, satisfying the NBR 15805 (ABNT, 2010), may also be utilized in the production of concrete pavements, and thus contributing to the reduction of scattered residues, in Reduction of damages to the environment and bringing savings to obtain SCC.

RESUMO: O objetivo deste é determinar o percentual de substituição de cimento por resíduos 


\section{INTRODUÇÃO}

Os resíduos gerados pelos estabelecimentos comerciais de corte, fabricação e montagem de artefatos de rochas ornamentais, da cidade de Manaus-AM, em sua maioria RMG, possuem dimensões que vão de grãos de pó até fragmentos de formatos irregulares alcançando até $25 \mathrm{~cm}$ de diâmetro. Esses são em muitos casos depositados em locais inadequados ou despejados na natureza sem passar por um tratamento adequado. Muitas dessas empresas por falta de conhecimento deixam esses RMG acumulados nos terrenos em torno das marmorarias ou os destinam aos depósitos de resíduos do município. Parte desses resíduos em forma de pó são levados por lixiviação e despejadas nos cursos d’água, sem o devido tratamento, contaminam diretamente os rios e o próprio solo, além da desfiguração da paisagem, o que desperta preocupação por parte da população e das autoridades.

No estado do Amazonas cada marmoraria movimenta de 400 a $1000 \mathrm{~m}^{2} /$ mês de rochas ornamentais, com produção de resíduos na ordem de $25 \%$, segundo Padilha dos Santos (2002), ou seja, são aproximadamente $5.000 \mathrm{~m}^{3}$ de material descartado por ano e que em sua maioria podem apresentar potencial de reutilização. Miranda (2012) estimou que no Brasil as marmorarias, no processo de serragem e o polimento das rochas ornamentais, produziam aproximadamente 190.000 toneladas de resíduo de beneficiamento de mármore e granito por ano. Segundo o Serviço Brasileiro de Apoio à Micro e Pequena Empresa (Sebrae), o país possui mais de 1.200 variedades de rochas ornamentais, exploradas por 12.000 empresas instaladas por todo o Brasil (SEBRAE, 2014).

Uma excelente alternativa para diminuição dos problemas supracitados seria a utilização desses resíduos em subprodutos na construção civil, levando-se em conta que este setor consome um grande volume de recursos naturais e se mostra propenso a absorver os resíduos sólidos. Um dos sistemas construtivos que vem ganhando aceitabilidade na indústria da construção civil e que vem sendo adotado por muitas empresas do sul e sudeste do país é o CAA. Alguns autores tratam esse assunto como uma das evoluções dos concretos convencionais que se mostra como sendo uma tecnologia que possui características nunca alcançadas com o concreto convencional. Trata-se de um concreto que têm como fundamento a utilização de aditivos químicos e adições minerais, que irão fazê-lo alcançar suas três principais propriedades no estado fresco: coesão, habilidade passante e resistência à segregação. Por possuir adensamento próprio, permite que o material tenha propriedades reológicas muito mais fluidas, aumentando sua área de atuação, já que é possível usar tal material para as mais diversificadas formas e com as armaduras mais densas projetadas. Apesar da tecnologia não ser exatamente nova, ainda não há um consenso teórico de como dosar um CAA, sendo que os traços são desenvolvidos de maneira experimental e os métodos teóricos já existentes, ainda não são muito populares, variando de pesquisador para pesquisador (PAUMGARTTEN, 2010).

Levando-se tudo isso em consideração percebe-se a possibilidade de se adicionar esses resíduos nas dosagens de concreto, em busca de uma destinação apropriada desses, ou como fíler ou como modificador de viscosidade.

\section{OBJETIVO}

Este trabalho tem como objetivo analisar a viabilidade técnica da utilização dos resíduos gerados nas marmorarias de Manaus na composição de CAA, em substituição parcial ao cimento e comparar as propriedades reológicas, físicas e mecânicas, desses CAA com um concreto de referência adotado, a saber: sem adição de resíduos.

\section{CONCRETO AUTOADENSÁVEL - CAA}

Um concreto será considerado CAA se três propriedades no estado fresco forem alcançadas simultaneamente: fluidez, coesão necessária para que a mistura escoe intacta entre barras de aço e 
outros embutidos (ou habilidade passante) e resistência à segregação (manter-se homogêneo) nas etapas de mistura, transporte, lançamento e acabamento. Fluidez é a capacidade do CAA de fluir dentro das fôrmas e preencher todos os espaços; Habilidade passante é a capacidade da mistura de escoar pelas formas, passando por entre as armaduras de aço sem obstrução do fluxo ou segregação; Resistência à segregação é a propriedade que define a capacidade do CAA de se manter coeso ao fluir dentro das fôrmas, passando ou não por obstáculos (NBR 15823, ABNT 2010). Essas propriedades são alcançadas com a introdução de aditivos químicos e de adição mineral como componentes do CAA. Os aditivos por melhorarem a fluidez da mistura e a adição mineral por causar aumento da densidade da mistura devido ao preenchimento dos vazios; o refinamento da estrutura de poros e dos produtos de hidratação do cimento, causados pelas pequenas partículas das adições que podem agir como pontos de nucleação para os produtos de hidratação; e a alteração da microestrutura da zona de transição, reduzindo ou eliminando o acúmulo de água livre que, normalmente, fica retido sob os agregados (TUTIKIAN e DAL MOLIN, 2008).

$\mathrm{O}$ resíduo de beneficiamento de rochas ornamentais é classificado como sendo de Classe III - Inerte. Portanto, a sua utilização na construção civil não causa risco ambiental e nem a saúde humana. Porém, a lama dos resíduos do beneficiamento do mármore e do granito (RBMG) quando descartada de forma incorreta pode causar graves problemas ambientais, como o assoreamento de rios, poluição dos mananciais, e também pode causar doenças à população (LOPES, 2006).

Considerando-se a grande quantidade de resíduo gerada e tentando contribuir para o desenvolvimento sustentável, alguns pesquisadores vêm estudando o aproveitamento de resíduos de rochas ornamentais na construção civil, como na produção de concretos convencionais: Santos, (2011), Gonçalves, J.P., (2002) e Barbosa, M.T., (2008); na produção de vidros: Marçal, R.L., (2011); em lajotas para piso: Moura, W.A., (2002); em placas em matriz polimérica: Molinari, É.J, (2007); em blocos de concreto: Rania A. Hamza, (2011); em blocos de solo cimento: Miranda, R.A.C., (2012); na produção de asfaltos: Stefenon. F, (2003); etc. No estado do Amazonas já houve contribuição de alguns pesquisadores na pesquisa de CAA com utilização de resíduos como, por exemplo: CAA com fibras de polipropileno: Sousa Filho, (2011); CAA com resíduo de vidro: Bartholomei, M.B., (2013).

\subsection{PROPRIEDADES REOLÓGICAS DO CAA}

O CAA é considerado um concreto especial porque possui diversas propriedades especiais já no estado fresco. É de suma importância conhecer essas propriedades para se prever o comportamento desse concreto por ocasião de seu transporte, bombeamento e lançamento nas formas. Deve possuir a capacidade de fluir nas direções vertical e horizontal sem a incorporação de ar ou acúmulo de bolhas superficiais. As forças que comandam esse processo são o peso próprio do concreto e sua energia de lançamento, somente pela ação do seu peso próprio, sem a aplicação de vibração ou de qualquer tipo de energia de compactação externa (MARANGON, 2011).

A necessidade de se tornar mais ou menos fluido leva a uma dosagem consequentemente diferente da dosagem do concreto convencional (CCV). A diferença principal entre o CAA e o CCV são as características reológicas. Essas características são conseguidas se aumentando a proporção de pasta cimento-agregado do que normalmente utilizada (MARQUES, 2011).

A classificação do CAA no estado fresco, segundo a NBR 15823 (ABNT, 2010), depende das seguintes características:
a) fluidez e escoamento;
b) viscosidade plástica aparente;
c) habilidade passante; e
d) resistência à segregação.

Para a determinação das características do concreto autoadensável no estado fresco, a NBR 15823:2010 prevê os seguintes ensaios:

a) o ensaio de espalhamento (SF) avalia o grau de fluidez e escoamento;

b) os ensaios espalhamento T500 (VS) e 
Funil V (VF) avaliam o grau de viscosidade plástica aparente;

c) os ensaios da Caixa L (PL) e do Anel J (PJ) avaliam a habilidade passante; e

d) o ensaio da Coluna de Segregação (SR) avalia a resistência à segregação.

Outros ensaios, além dos adotados pela NBR 15823:2010 (ABNT. 2010), também estabelecem padrões para classificação, controle e aceitação do CAA no estado fresco. A seguir, são relacionados alguns exemplos desses ensaios:

a) o ensaio do Tubo $U$ (RS) avalia a resistência à segregação;

b) os ensaios Orimet (TO) e Caixa U avaliam simultaneamente o grau de fluidez e escoamento, a habilidade passante e a resistência à segregação; e

c) o ensaio da Coluna de Rooney avalia a resistência à segregação (SOUSA FILHO, 2011).

\subsection{PROPRIEDADES MECÂNICAS DO CAA}

Com relação às propriedades mecânicas o CAA é muito parecido com o CCV no estado endurecido. O CAA aplicado na indústria de prémoldado atendeu todas as expectativas quanto à resistência à compressão, durabilidade e garantindo a estanqueidade da peça. Apresentou valores maiores no custo de produção, mas como a resistência do concreto ficou acima dos valores estimados será possível equilibrar o custo final (BERTOCINI, 2013).

Marangon (2011) lembra que a resistência à compressão é a propriedade mecânica do concreto mais utilizada, pois é a partir dela que se faz a classificação do material e, indiretamente, prevê-se a sua durabilidade. O diagrama tensãodeformação do material, obtido através de ensaios experimentais de compressão, possibilita a determinação de sua resistência à compressão, módulo de elasticidade, deformação máxima e capacidade de absorção de energia (MARANGON, 2011).

Tutikian e Dal Molin (2008) afirmam que essas propriedades são resultados de decisões tomadas na dosagem. Segundo eles o CAA apresentará fissuração de secagem e alto calor de hidratação se for dosado com alto teor de cimento; se o teor de superplastificante for excessivo terá sua pega inicial retardada; se for dosado com baixo consumo de agregados graúdos seu módulo de elasticidade será baixo e terá maior probabilidade de retração plástica. Com respeito ao adensamento o CAA não apresenta problemas, enquanto que o $\mathrm{CCV}$, se cuidados não forem tomados, tem sua qualidade final comprometida. Além dos poros da pasta do cimento e dos agregados, o concreto como um todo possui vazios causados tanto por adensamento incompleto como por exsudação. Esses vazios ocupam de 1 a $10 \%$ de seu volume, sendo que misturas com valores de $10 \%$ são as que têm muitas falhas e resistências muito baixas. A atividade de lançamento também é intensificada uma vez que se exige menos habilidade para se obter um produto uniforme $\mathrm{e}$ denso. As propriedades no estado endurecido são iguais ou superiores às do CCV equivalentes. Isso leva a crer que o adensamento $e$, consequentemente, a durabilidade do concreto é mais garantido com a utilização do CAA, uma vez que um possível erro humano, na forma de adensamento inadequado, se torna consideravelmente reduzido (TUTIKIAN e DAL MOLIN, 2008).

\subsection{PROPRIEDADES FÍSICAS E QUÍMICAS DO CAA}

As propriedades físicas e químicas do CAA também são altamente influenciadas por fatores que podem comprometer sua qualidade como produto final, entre as físicas estão a absorção, o índice de vazios e a massa específica real do CAA. Uma das propriedades químicas a ser considerada é a RAA, que se existente pode causar patologias de deterioração no concreto endurecido.

Absorção representa a quantidade de água absorvida pelo material seco com relação a massa do material e é representado em porcentagem. A penetração e movimentação de água no concreto é função da quantidade, forma, distribuição e dimensões dos poros do concreto (NBR9777, ABNT. 1987).

A maioria das pesquisas sobre o assunto alcançaram valores de absorção próximo de $10 \%$, Sato (1998) 12,8 a 15,8\%, Barbosa (2008) 7,58\%, 
Barros (2008) 7,87 a 13,87\%, López (2005) 11,35\%, este último para o concreto de referência.

A RAA é um tipo de reação expansiva que ocorre devido ao processo químico que provém dos compostos mineralógicos do agregado com hidróxidos alcalinos originários do cimento, água de amassamento e agentes externos, os quais estão dissolvidos nas soluções dos poros do concreto, cujo produto final é um gel cristalino expansivo na presença de umidade, podendo originar fissuras, aumento da permeabilidade, diminuição da resistência e consequentemente ruptura da estrutura (BAPTISTA, et al. 2013).

A norma NBR 15577-4 (ABNT, 2008) classifica os materiais utilizados no concreto de acordo com a expansão obtida no ensaio, assim se a expansão das barras ensaiadas for superior a $0,20 \%$ o material é reativo; expansões entre $0,10 \%$ e 0,20\% o material é potencialmente ativo; e; para barras com expansões menores que $0,10 \%$ o material é considerado inócuo.

\subsection{USO DE ADIÇÕES MINARAIS E DE ADITIVOS QUÍMICOS NO CONCRETO}

Correia Gomes, P. C. C. e Barros, A. R. (2009) define adições minerais como materiais que são finamente moídos e são incorporados ao concreto com a finalidade de obter características especiais, como por exemplo, reduzir os custos e melhorar a trabalhabilidade do concreto no estado fresco, podendo até melhorar a sua resistência à fissuração térmica, à expansão álcali agregado e ao ataque de sulfatos.

Fonseca, G.C. (2010) diferencia aditivo químico de adição mineral esclarecendo que o primeiro altera as características do cimento, sem alterar sua proporção na composição do concreto enquanto a adição, como o próprio nome sugere, serve para somar ou substituir parcialmente o cimento, devido às suas propriedades semelhantes às do cimento.

O efeito químico das adições minerais ocorre a partir da capacidade de reação com o hidróxido de cálcio - $\mathrm{Ca}(\mathrm{OH}) 2$ - composto frágil e solúvel que forma durante a hidratação do cimento Portland. Dele deriva um composto resistente, o CS-H (silicato hidratado de cálcio), que ocupa os vazios de maiores dimensões existentes na pasta de cimento ou na zona de transição, aumentando o desempenho mecânico e a durabilidade do concreto, pois origina uma pasta mais densa e homogênea, substituindo poros grandes por menores, o que dificulta o ingresso e deslocamento de agentes agressivos no interior da pasta, ilustrado na Figura 1-a. $O$ resultado é um maior empacotamento com o cimento, promovendo o aumento da resistência do concreto, como ilustrado na Figura 1-b (ANDRADE, 2012).

Já o efeito físico pode ser desdobrado em três ações principais: o efeito filer, que é o aumento da densidade da mistura resultante do preenchimento dos vazios pelas minúsculas partículas das adições; o refinamento da estrutura de poros e dos produtos de hidratação do cimento, causados pelas pequenas partículas das adições que podem agir como pontos de nucleação para os produtos de hidratação; e a alteração da microestrutura da zona de transição, reduzindo ou eliminando o acúmulo de água livre que, normalmente, fica retido sob os agregados (TUTIKIAN e DAL MOLIN, 2008).

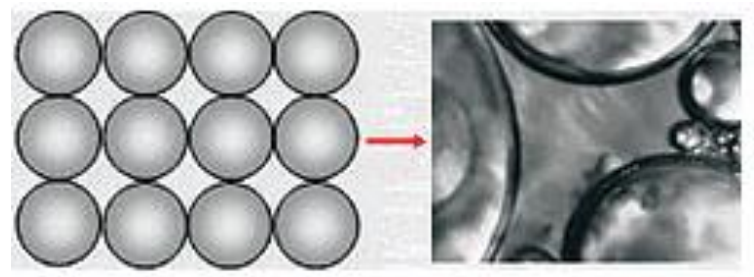

(A)

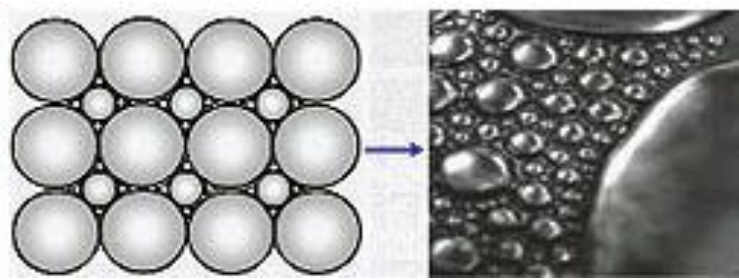

(B)

FIGURA 1: Empacotamento das partículas com o cimento: (a) Falha de empacotamento; (b) Empacotamento adequado. FONTE: (ANDRADE, 2012). 
A NBR 11768 (ABNT, 1990), define aditivo químico o produto que adicionado em pequenas quantidades, modifica algumas propriedades do concreto, no sentido de melhor ajudá-las em determinadas condições, ou seja, o concreto precisa ter, antecipadamente, determinada característica para que $o$ aditivo possa acentuar, retardar, acelerar ou plastificar.

Tutikian e Dal Molin (2008) classificam os superplastificantes em quatro categorias, de acordo com sua composição química:

a) Ignossulfonados ou lignossulfonados modificados (LS). Esses geralmente incorporam ar e retardam, com diversas intensidades, a pega do cimento;

b) Sais sulfonados de policondensado de naftaleno e formadeído, usualmente denominados de naftaleno sulfonado ou apenas de naftaleno (NS). Estes compostos não incorporam ar e praticamente não interferem no tempo de pega do cimento;

c) Sais sulfonados de policondensado de melamina e formadeído, usualmente denominado de melamina sulfonato ou apenas de melamina (MS). A melamina pode apresentar uma tendência a retardar a pega do cimento e, eventualmente, incorporar pequena quantidade de ar;

d) Policarboxilatos (PC).

Os policarboxilatos (PC) são os aditivos mais aconselhados para utilização no CAA, por serem aditivos superplastificantes de alta eficiência que dispersam e defloculam as partículas de cimento. Assim, permitem a redução de água das misturas de até 40\%, mantendo a mesma trabalhabilidade. Também são poliméricos, melhoram sensivelmente a dispersão das partículas de cimento quando comparados aos aditivos de primeira e segunda geração, uma vez que os tradicionais são baseados em polímeros as partículas de cimento absorvem e que acumulam-se em sua superfície. Como esses polímeros aumentam a carga negativa, desbalanceando, do cimento, fazem com que suas partículas se dispersem por repulsão elétrica, exigindo menos água para fluidificar a pasta (TUTIKIAN e DAL
MOLIN, 2008).

\subsection{APROVEITAMENTO DE RESÍDUOS PÉTREOS - ROCHAS ORNAMENTAIS}

A NBR 6502 (ABNT, 1995) define rocha como sendo material sólido, consolidado e constituído por um ou mais minerais. As rochas ornamentais e para revestimento, também designadas pedras naturais, rochas lapídeas, rochas dimensionais e materiais de cantaria, compreendem os materiais geológicos naturais que podem ser extraídos em blocos ou placas, cortados em formas variadas e beneficiados por meio de esquadrejamento, polimento, lustro, etc. Seus principais campos de aplicação incluem tanto o emprego em peças isoladas, como esculturas, tampos e pés de mesa, balcões, lápides e artefatos de arte funerária em geral, quanto em edificações, destacando-se, nesse caso, os revestimentos internos e externos de paredes, pisos, pilares, colunas, soleiras, etc. (CHIODI e RODRIGUES, 2009).

Considerando o lado comercial, as rochas ornamentais são definidas essencialmente à luz de duas principais categorias, que são os "granitos" e os "mármores", distinguidas com base na sua composição mineralógica. Os granitos abrangeriam as rochas silicatadas, ou seja, formadas por minerais estruturalmente constituídos por tetraedros de SiO4, ao passo que os mármores incluiriam as rochas composicionalmente carbonásticas (LARIZZATTI e MENESES, 2005).

Segundo Chiodi e Rodrigues (2009), o mármore e o granito respondem largamente pelas variedades de rochas ornamentais e de revestimento comercializadas, representando cerca de $80 \%$ da produção mundial. No Brasil, estudos indicam que os granitos correspondem a $50 \%$ do total de consumo a produção nacional de rochas ornamentais, enquanto apenas $19 \%$ são relativos aos mármores.

No Brasil existem mais de 1000 jazidas de mármores e granitos (MIRANDA, 2012). A extensa extração e tratamento das rochas colocou o país como $8^{\circ}$ colocado no ranking de países exportadores de blocos e é o 5o maior exportador de rochas ornamentais acabadas (SEBRAE, 2014). 
Segundo a revista Qualidade (2004) são produzidos aproximadamente, mais de dois milhões de metros cúbicos de blocos por ano, mais de quarenta milhões de metros quadrados de chapas e mais de três milhões de ladrilhos padronizados. De acordo com Lopes (2006), aproximadamente $20 \%$ a $30 \%$ das rochas são desperdiçadas na forma de lama devido ao processo produtivo utilizado na indústria de beneficiamento de rochas ornamentais. No ano de 2009 o Brasil explorou 7,6 milhões de toneladas de pedras ornamentais, tendo participação da região norte de 1,3\%, com 100.000 toneladas produzidas (CHIODI e RODRIGUES, 2009). A Figura 2 ilustra as placas já beneficiadas, no ponto de corte para uso na construção civil.

A utilização de resíduo de beneficiamento de rochas ornamentais na construção civil não causa risco ambiental e nem a saúde humana. Porém, a lama dos resíduos do beneficiamento do mármore e do granito quando descartada de forma incorreta pode causar graves problemas ambientais, como o assoreamento de rios, poluição dos mananciais, e também pode causar doenças à população (LOPES, 2006).

São dois os produtos finais: o primeiro é a peça desejada que poderá ser fixada no local planejado e estará pronta para uso, como mostra a Figura 3-a; o segundo é o resíduo, que são de dimensões variadas, as maiores depositadas nas dependências da empresa, como mostra a Figura 3b, e na forma de pó misturado à água, formando lama, é levado através de caneletas no piso até um pequeno tanque de decantação. A lama é retirada e deixada secar.

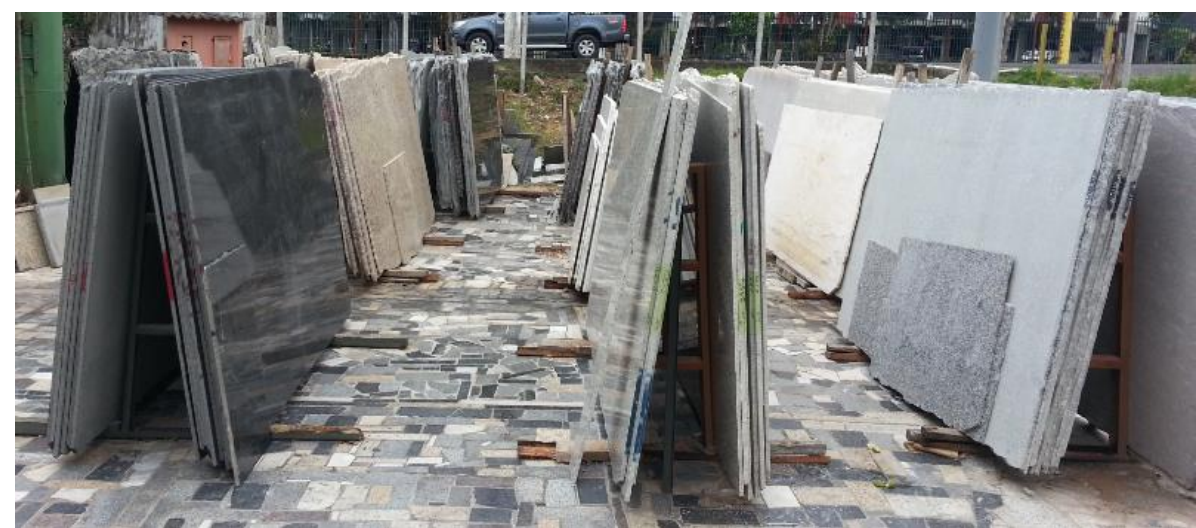

FIGURA 2: Placas no pátio da marmoraria. FONTE: Fotografia do local.

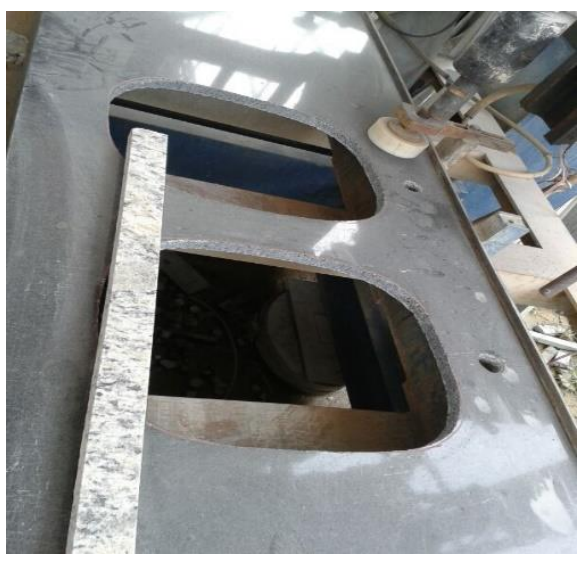

(a)

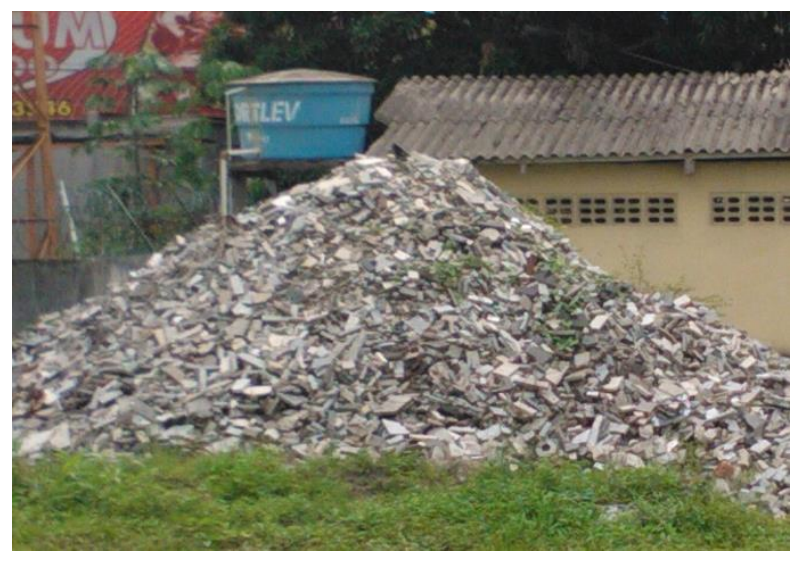

(b)

FIGURA 3: Produtos finais do corte da placa: (a) Peça projetada; (b) Aparas de mármores e granitos provenientes do corte de placas.

FONTE: Fotografia do local. 
Esses resíduos pulverulentos são compostos pela mistura dos diversos minerais que constituem as rochas em placas ali beneficiadas, uma vez que não há uma preocupação com a separação prévia dos resíduos provenientes dos dois tipos de placas. Torna-se necessário que se conheça as características físicas, químicas e mineralógicas desse resíduo. Algumas diferenças entre as rochas podem ser constatadas facilmente. O mármore é uma rocha metamórfica, formada pelo metamorfismo de calcários, composta pelos minerais calcita e dolomita, como ilustra a Figura 4a. Já o granito é uma rocha eruptiva plutônica supersaturada, composta pelos minerais: quartzo, feldspato, mica e outros, conforme ilustra a Figura 4-b. Ambos possuem boa condutividade térmica, são poroso quando não polidos, possuem superfície antiderrapante, são muito resistentes a choques e intempéries, com durezas na escala de Mohs de 3,0 a 4,5 para o mármore e de 5,0 a 7,0 para o granito (BARROS FILHO, 2005).

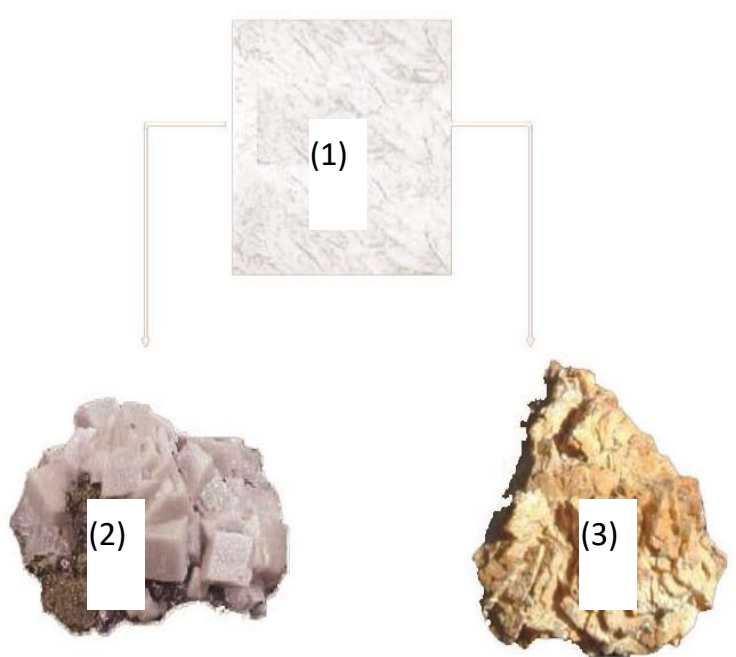

(a)

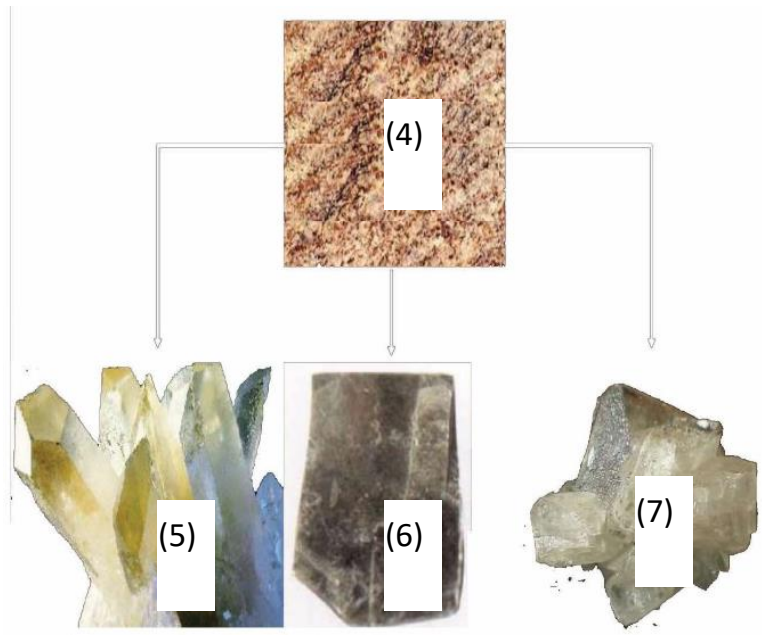

(b)

FIGURA 4: Esquema da composição mineralógica típica: a) do mármore (1): calcita (2) e dolomita (3); b) do granito (4): Quartzo (5), mica (6) e feldspato (7).

FONTE: BARROS FILHO (2005).

\section{ESTUDO EXPERIMENTAL}

A metodologia para alcance do objetivo principal se deu a partir de experimentos em laboratório, primeiramente para caracterização dos materiais a serem partes constituintes do CAA, o que levou à segunda etapa que foi a produção de vários traços de CAA com diferentes percentuais de adição mineral, seguido da moldagem de corpos de prova e de placas de CAA, ensaios no estado fresco para classificação do destino e das possíveis aplicações, uma terceira etapa com ensaios de resistência à compressão e à flexão no estado endurecido, e por último ensaios de absorção de água, índice de vazios e de massa específica real e de ensaios em barras de argamassas para determinação de possível RAA.

As nomenclaturas adotadas para os concretos produzidos são os apresentados na Tabela 1.

Um concreto de referência, ou seja, sem adição de resíduo, para cada um dos superplastificantes, três concretos autoadensáveis com adição de resíduo RMG nas respectivas porcentagens de substituição de cimento em massa: 10\%, 15\%, 20\% para o superplastificante Sika e de $5 \%, 10 \%, 20 \%, 30 \%$ e $40 \%$ para o superplastificante Powerflow, ambos percentuais sobre a massa do cimento. 
Tabela 1: Concretos produzidos.

\begin{tabular}{ccc} 
Misturas & \% de RMG & Superplastificante \\
\hline & & \\
CS0 & 0 & SIKA \\
CS10 & 10 & SIKA \\
CS15 & 15 & SIKA \\
CS20 & 20 & SIKA \\
CW0 & 0 & POWERFLOW \\
CW5 & 5 & POWERFLOW \\
CW10 & 10 & POWERFLOW \\
CW20 & 20 & POWERFLOW \\
CW30 & 30 & POWERFLOW \\
CW40 & 40 & POWERFLOW \\
\hline
\end{tabular}

\subsection{TEOR ÓTIMO DE SUPERPLASTIFICANTES}

O método empregado para determinação do teor ótimo de superplastificante, o funil de Marsh, tem objetivo de avaliar a compatibilidade e o ponto de saturação do dispersante sobre as partículas finas. Trata-se de um ensaio de fluidez de pastas, adaptado da norma NBR 7681 (ABNT, 2013). $O$ método consiste em medir o tempo que determinada quantidade de pasta leva para fluir através de um funil com diâmetro pré-determinado, utilizado por Aïtcin (2000), que na pesquisa essa quantidade foi de $900 \mathrm{ml}$, com diâmetro do funil de $5 \mathrm{~mm}$. O procedimento adotado está ilustrado na
Figura 6.

\subsection{DOSAGEM EXPERIMENTAL DO CONCRETO}

A dosagem do concreto de referência foi baseada no método da Associação Brasileira de Cimento Portland (ABCP). Sendo assim, o traço determinado neste estudo foi de: 1 : 1,15:1,80 : 0,41 (cimento: agregado miúdo: agregado graúdo: fator água/cimento), estimando-se uma resistência à compressão axial mínima aos 28 dias de idade igual a $35 \mathrm{MPa}$, que é a resistência mínima exigida para placas de concreto para piso, conforme estabelece a NBR 15805 (ABNT, 2010).

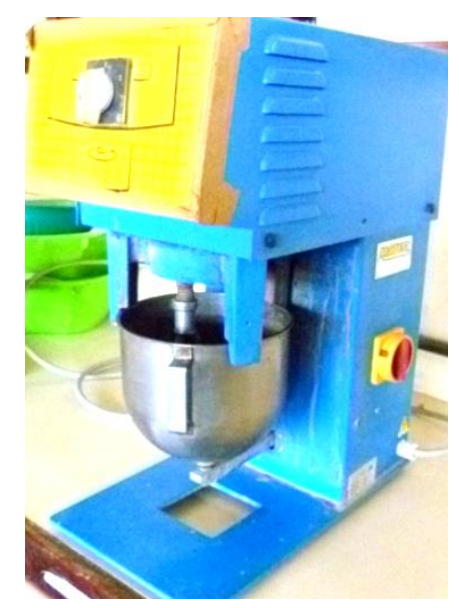

(a)

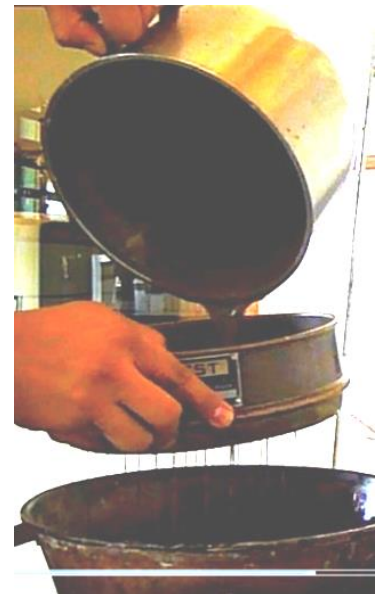

(b)

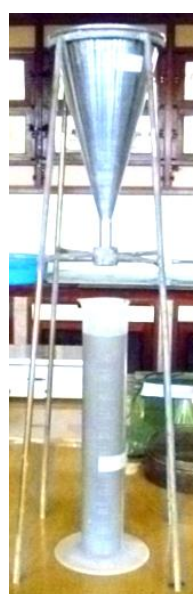

(c)

FIGURA 5: Procedimentos para determinação do percentual ótimo de superplastificante: (a) Misturados insumos no misturador planetário; (b) Peneiramento da calda: (c) Medida do tempo de escoamento no funil de Marsh.

FONTE: Fotografia do local. Autoria própria. 


\subsection{PROPRIEDADES REOLÓGICAS}

Para determinação das propriedades reológicas os ensaios basearam-se na norma NBR 15823 (ABNT, 2010), que estabelece ensaios especiais para estudo das três características especiais do CAA: fluidez, habilidade passante e resistência à segregação.

Os ensaios do concreto no estado fresco realizados foram: a) De espalhamento, conhecidos como slump flow e slump flow T50; b) De fluidez no funil V, conhecido na literatura como V-funnel e Vfunnel $5 \mathrm{~min}$; e; c) De habilidade passante na caixa "L", chamado pelos escritores como L-Box. Todos esses estão ilustrados nas Figuras 6 a 9. Os valores normatizados na NBR 15823 (ABNT, 2010) estão descritos nas Tabelas 2 a 5 .

A ABNT NBR 15823 (ABNT, 2010) classifica o CAA e sugere sua aplicação de acordo com o valor obtido nesse ensaio e descritos na Tabela 2.

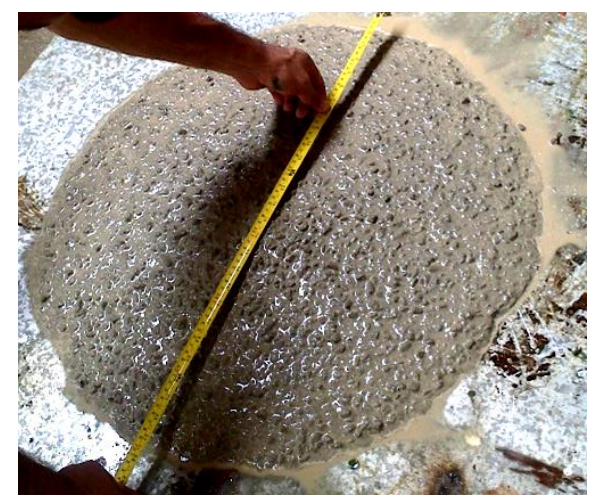

(a)

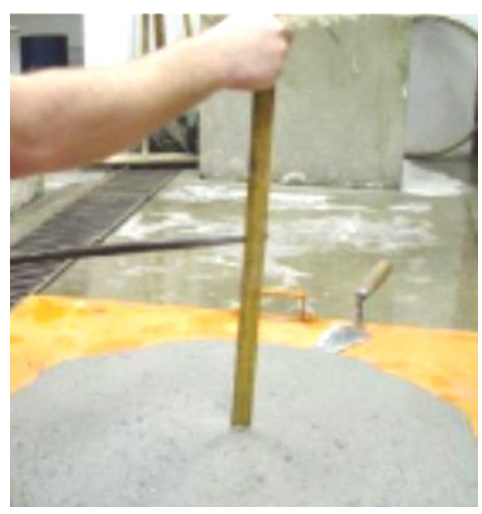

(b)

FIGURA 6: Medidas do abatimento e do espalhamento: (a) Medida do abatimento; (b) Medida do espalhamento no ensaio do "slump". Fonte: Marangon, 2011, pg 57.

FONTE: Fotografia do local. Autoria própria.

TABELA 1: Classes de espalhamento, aplicação e exemplo de utilização do CAA em função do ensaio de slump flow, segundo a NBR 15823 (ABNT, 2010).

\begin{tabular}{|c|c|c|c|c|}
\hline $\begin{array}{l}\text { Propriedades } \\
\text {. Ensaios. }\end{array}$ & & asses & Aplicação & Exemplo \\
\hline \multirow{6}{*}{$\begin{array}{l}\text { Espalhament } \\
\text { o (Slump } \\
\text { flow) }\end{array}$} & SF 1 & $550 \mathrm{a}$ & $\begin{array}{l}\text { estruturas não armadas ou com baixa taxa de } \\
\text { armadura e embutidos, cuja concretagem é } \\
\text { realizada a partir do ponto mais alto com } \\
\text { deslocamento livre. }\end{array}$ & Lajes. \\
\hline & 650 & $\mathrm{~mm}$ & concreto autoadensável bombeado; & $\begin{array}{l}\text { Revestimento de } \\
\text { túneis. }\end{array}$ \\
\hline & & & $\begin{array}{l}\text { estruturas que exigem um curto espalhamento } \\
\text { horizontal do concreto autoadensável. }\end{array}$ & $\begin{array}{l}\text { Estacas e certas } \\
\text { fundações } \\
\text { profundas. }\end{array}$ \\
\hline & SF 2 & 660 a & & Paredes, vigas, \\
\hline & 750 & $\mathrm{~mm}$ & adequada para a maioria das aplicações correntes; & pilares e outros \\
\hline & $\begin{array}{l}\text { SF } 3 \\
850\end{array}$ & $\begin{array}{l}750 \mathrm{a} \\
\mathrm{mm}\end{array}$ & $\begin{array}{l}\text { estrutura com alta taxa de armadura e/ou de } \\
\text { forma arquitetônica complexa, com o uso de } \\
\text { concreto com agregado graúdo de pequenas } \\
\text { dimensões (menor que } 12,5 \mathrm{~mm} \text { ); }\end{array}$ & $\begin{array}{l}\text { Pilares-parede, } \\
\text { paredes } \\
\text { diafragma e } \\
\text { pilares. }\end{array}$ \\
\hline
\end{tabular}

FONTE: NBR 15823 (ABNT, 2010). 
O slump flow test $T 50 \mathrm{~cm}$ é uma variação do slump flow, já que o procedimento e os equipamentos são os mesmos. As únicas alterações são a marcação de um círculo de $500 \mathrm{~mm}$ de diâmetro centrado na base e a necessidade de um cronômetro para a realização do teste (ABNT-NBR15823-2, 2010). Assim que o cone for erguido verticalmente deve-se acionar o cronômetro e marcar o tempo em que o concreto alcança a marca dos $500 \mathrm{~mm}$. Se o tempo for baixo, indica que o concreto está muito fluido; se o tempo for alto, indica que o concreto está muito coeso e deve, em ambos os casos, ser corrigido. A Figura 7-a ilustra o ensaio, no qual o espalhamento do CAA está próximo à marcação do círculo de $500 \mathrm{~mm}$ de diâmetro.

A ABNT NBR 15823 (ABNT, 2010) classifica - CAA, sugere sua aplicação e exemplifica sua utilização de acordo com o valor obtido nesse ensaio e descritos na Tabela 3.

$\mathrm{O}$ ensaio de escoamento no funil $\mathrm{V}$ mede a fluidez e resistência à segregação do concreto, sendo apropriado para agregados graúdos de diâmetro máximo de $20 \mathrm{~mm}$. A Figura 7-b ilustra o equipamento utilizado que consiste em medir o tempo de escoamento de CAA. Para o ensaio com funil V a ABNT NBR 15823 classifica o CAA e sugere sua aplicação, bem como exemplifica sua utilização de acordo com o valor obtido nesses ensaios e descritos na Tabela 4.

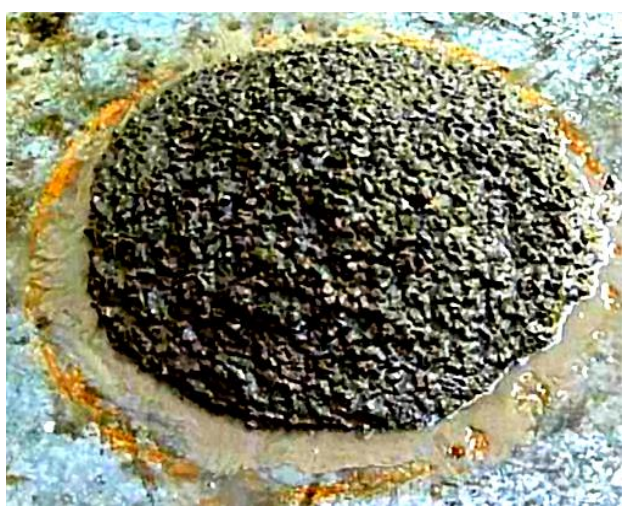

(a)

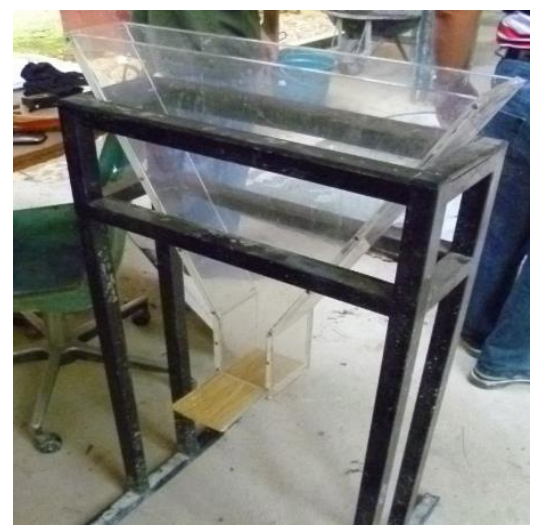

(b)

FIGURA 7: Ensaios reológicos: (a) Ensaio do Slump flow T50cm; (b) Ensaio de fluidez no Funil " V"*. FONTE: Fotografia do local. Autoria própria.

TABELA 3: Classes de espalhamento, aplicação e exemplo de utilização do CAA em função do ensaio de slump flow T50, segundo a NBR 15823 (ABNT,2010).

\begin{tabular}{|c|c|c|c|}
\hline Classe & $\begin{array}{l}\text { Viscosidad } \\
\text { e plástica } \\
\text { aparente } \\
\text { t500 (s) }\end{array}$ & Aplicação & Exemplo \\
\hline \multirow{2}{*}{ VS 1} & \multirow[t]{2}{*}{$\leq 2$} & $\begin{array}{c}\text { Adequada para elementos estruturais com alta densidade } \\
\text { de armadura e embutidos, mas exige controle de } \\
\text { exsudação e de segregação; }\end{array}$ & \multirow[t]{2}{*}{$\begin{array}{c}\text { Lajes, paredes-diafragma } \\
\text { pilares-parede, indústria } \\
\text { de pré-fabricados e } \\
\text { concreto aparente }\end{array}$} \\
\hline & & $\begin{array}{l}\text { Concretagens realizadas a partir do ponto mais alto com } \\
\text { deslocamento livre; }\end{array}$ & \\
\hline \multirow{3}{*}{ VS 2} & & Adequado para a maioria das aplicações correntes. & \multirow{3}{*}{ Vigas, pilares e outras } \\
\hline & & $\begin{array}{l}\text { Apresenta efeito tixotrópico que acarreta menor pressão } \\
\text { sobre as fôrmas e melhor resistência à segregação; }\end{array}$ & \\
\hline & $>2$ & $\begin{array}{c}\text { Efeitos negativos podem ser obtidos com relação à } \\
\text { superfície de acabamento (ar aprisionado) no } \\
\text { preenchimento de cantos e suscetibilidade e interrupções } \\
\text { ou demora entre sucessíveis camadas; }\end{array}$ & \\
\hline
\end{tabular}


TABELA 4: Classes de viscosidade plástica aparente do CAA em função dos tempo de escoamento no funil V, segundo a NBR 15823 (ABNT,2010).

$\begin{array}{ll} & \text { Viscosidade } \\ \text { Classe } & \text { plástica } \\ & \text { aparente } \\ & \text { Funil V (s) }\end{array}$

Aplicação

Exemplo

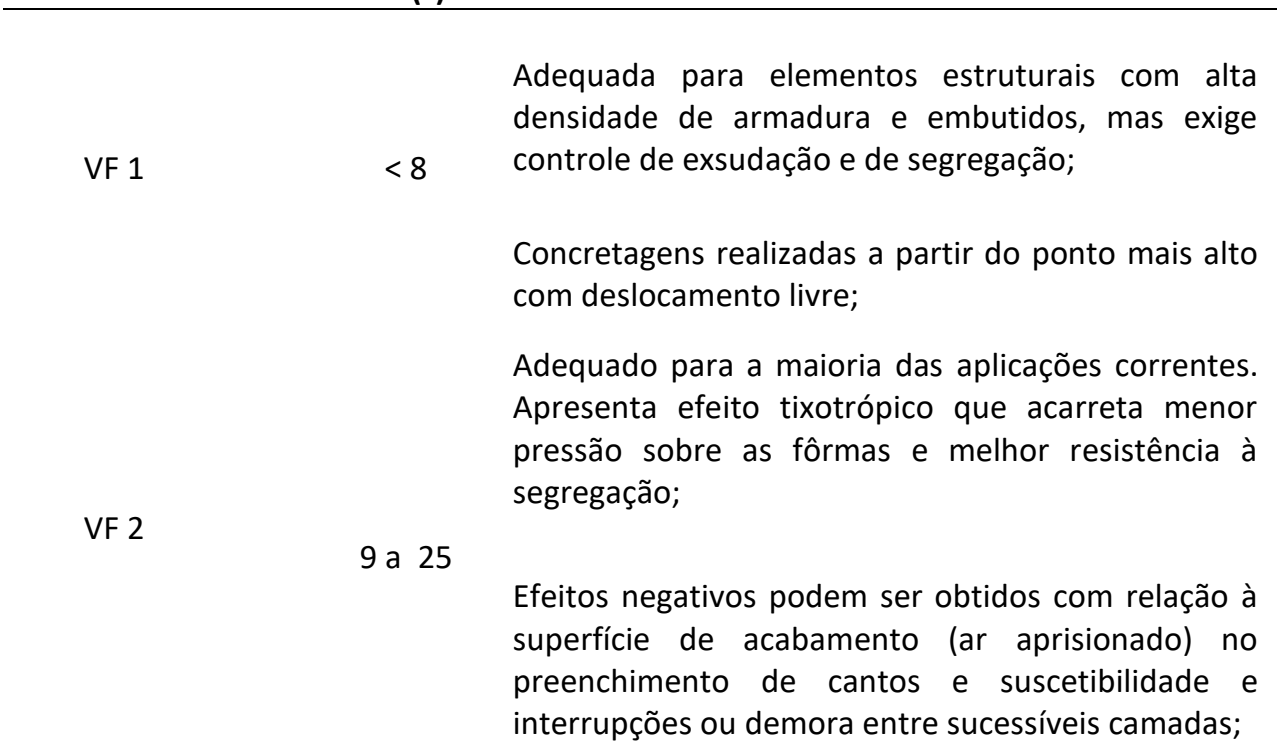

FONTE: NBR 15823 (ABNT, 2010).

O ensaio da caixa " $\mathrm{L}$ " mede a fluidez do concreto simultaneamente à sua capacidade de passar por obstáculos e permanecer coeso. 0 equipamento consiste em uma caixa em forma de "L" com uma porta móvel separando a parte vertical da horizontal e, junto com a divisória, barras de aço que simulam a estrutura, criando um obstáculo à
Lajes, paredes-

diafragma, pilaresparede, indústria de pré-fabricados concreto aparente.

Vigas, pilares e outras. 
TABELA 5: Classes de habilidades passante do CAA em função dos valores obtidos na caixa L, segundo a NBR 15823 (ABNT, 2010).

\begin{tabular}{|c|c|c|c|}
\hline Classe & $\begin{array}{l}\text { Habilidade Passante } \\
\text { Caixa L (H2/H1) }\end{array}$ & Aplicação & Exemplo \\
\hline PJ1 & $\begin{array}{l}\geq 0,80, \text { com } 2 \text { barras de } \\
\text { aço }\end{array}$ & $\begin{array}{l}\text { Adequada para elementos estruturais } \\
\text { com espaçamentos de armadura de } 80 \\
\mathrm{~mm} \text { a } 100 \mathrm{~mm} \text {; }\end{array}$ & $\begin{array}{lr}\text { Lajes, } & \text { painéis, } \\
\text { elementos } & \text { de } \\
\text { fundação. }\end{array}$ \\
\hline PJ2 & $\begin{array}{l}\geq 0,80 \text { com } 3 \text { barras de } \\
\text { aço. }\end{array}$ & $\begin{array}{l}\text { adequada para a maioria das aplicações } \\
\text { correntes. Elementos estruturais com } \\
\text { espaçamentos de armadura de } 60 \mathrm{~mm} \text { a } \\
80 \mathrm{~mm} \text {; }\end{array}$ & $\begin{array}{l}\text { Vigas, pilares, } \\
\text { tirantes, indústria } \\
\text { de pré-moldados. }\end{array}$ \\
\hline
\end{tabular}

FONTE: NBR 15823 (ABNT, 2010).

\subsection{PROPRIEDADES NO ESTADO ENDURECIDO}

Para determinação das propriedades mecânicas os ensaios se basearam nas normas NBR 5739 (ABNT, 2007), NBR 7215 (ABNT, 1997), NBR 15805 (ABNT, 2010) e NBR 6118 (ABNT, 2014). O objetivo era obter um CAA com RMG, em substituição ao cimento, com resistência à compressão maior que $35 \mathrm{MPa}$ e resistência à flexão maior que 4,5 $\mathrm{MPa}$, valores exigidos para placas de concreto para pavimentos, como mostram as Figuras 9-a e 9-b.

\subsection{PROPRIEDADES FÍSICAS E QUÍMICAS}

Para determinação dessas propriedades foram realizados ensaios de absorção de água, índice de vazios e de massa específica, com base nas especificações da norma NBR 9777 (ABNT, 1987) e ensaio de medida de expansão de barras de argamassas e concretos para medição dos efeitos de uma possível reação álcali-agregado, com base na norma NBR 15577-4 (ABNT, 2009), mostrado na figura 10.

O percentual de expansão indica a classificação do material como sendo reativo, potencialmente reativo ou inócuo, respectivamente para valores de $0,20 \%$ ou superior, entre $0,10 \%$ e $0,20 \%$, e, menor que $0,10 \%$ de expansão das barras de argamassa.

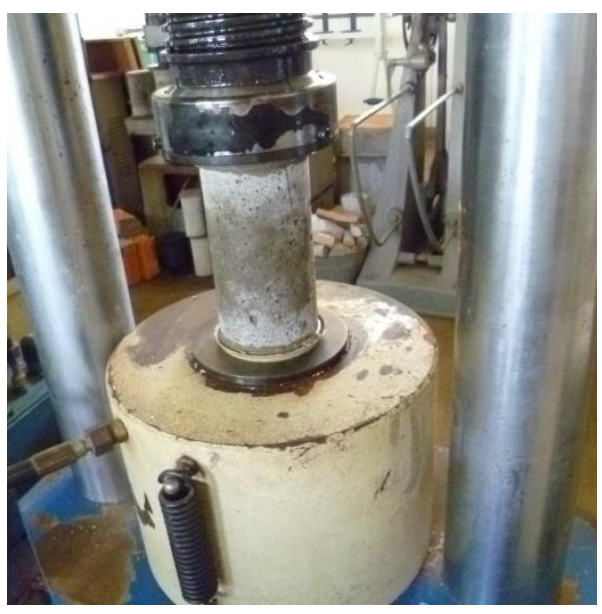

(a)

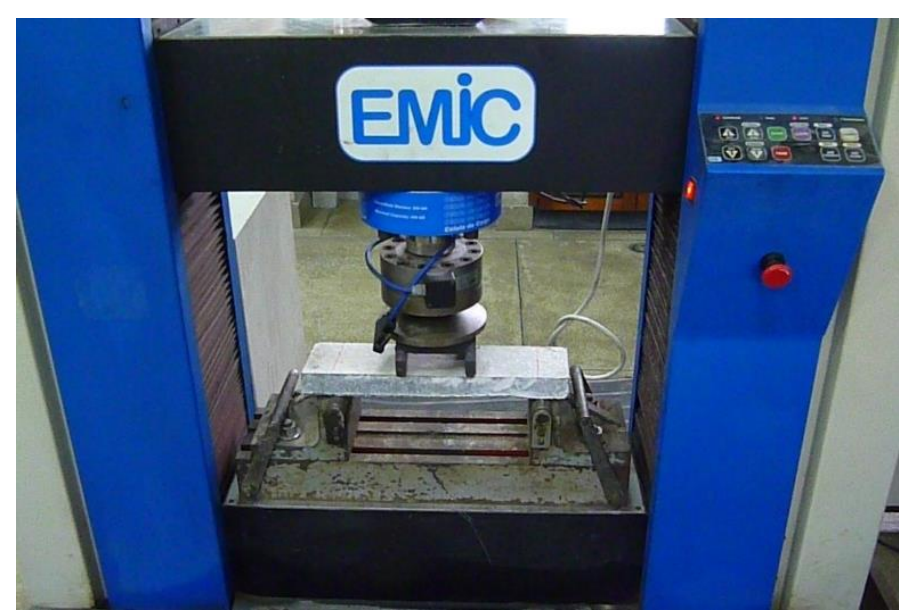

(b)

FIGURA 9: Ensaios mecânicos: (a) de compressão axial simples; (b) de flexão em 4 apoios.

FONTE: Fotografia do local. Autoria própria. 


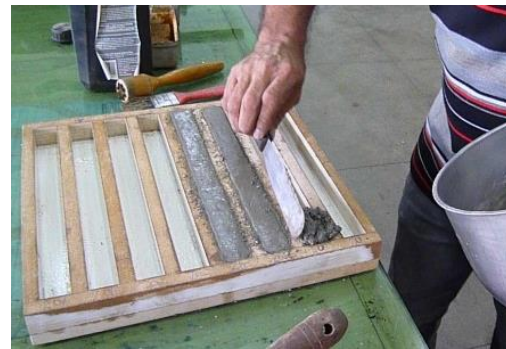

(a)

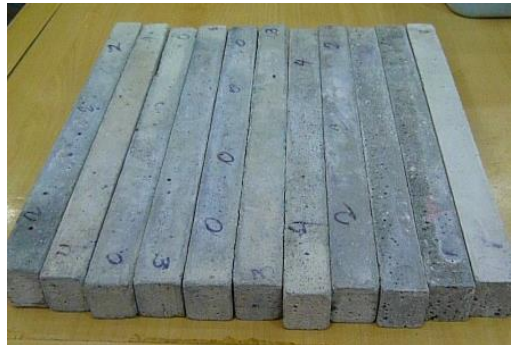

(b)

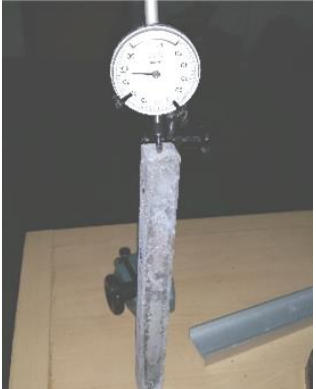

(c)

FIGURA 10: Ensaio para avaliação da reação álcali-agregado: (a) moldagem das barras. (b) barras de argamassas curadas; (c) medida dos comprimentos das barras com relógio comparador.

FONTE: Fotografia do local. Autoria própria.

\section{RESULTADOS E DISCUSSÃO}

\subsection{COMPOSIÇÃO QUÍMICA DO RMG}

A Tabela 6 mostra os resultados obtidos para ensaios de finura do cimento e tempo de pega para o cimento CP-I-32 utilizado. A peneira recomendada pela norma brasileira e utilizada foi a \# 200, conforme a NBR 11579 (ABNT, 2012).

Para se fazer uma avaliação da resistência do cimento foram realizados alguns corpos de prova de argamassa no traço 1:3 (uma parte de cimento para três partes de areia, em massa), com fator a/c $=0,48$ e submetidos a ensaio de compressão aos 3 , 7 e 28 dias, de acordo com o que especifica a ABNT. NBR 7215 (ABNT, 1997). A Tabela 7 mostra os resultados obtidos.

Pode-se constatar que a resistência dos corpos de prova constituídos de argamassa encontrava-se de acordo com o oferecido pelo fabricante do cimento, que era de $32 \mathrm{MPa}$, e que a utilização desse cimento no prosseguimento da pesquisa poderia ser mantida. $O$ valor foi ultrapassado já aos 28 dias e para a idade de 90 dias alcançou-se valores médios de resistência à compressão de $44,30 \mathrm{MPa}$, maior que a resistência esperada e indicada na embalagem do próprio cimento.

\subsection{PROPRIEDADES FÍSICAS E QUÍMICA DO RMG}

A Tabela 8 apresenta as propriedades de massa específica, forma física e módulo de finura do RMG.

Observa-se que a massa específica dos resíduos é muito próxima da massa específica dos agregados graúdos e dos agregados miúdos e dos valores encontrados na literatura. As massas específicas dos materiais constituintes do CAA apresentaram-se bem próximas, entre 2,56 e 2,66 $\mathrm{Kg} / \mathrm{cm}^{3}$, isso contribui em muito para que o produto final misturado tenham boa coesão e ajuda a manter uma resistência à segregação no concreto.

A composição química dos RMG obtida por fluorescência de raio-x é apresentada na Tabela 9.
Material retido $(\mathrm{g})$

1,21

1,28

Valor médio
Material retido (\%)

2,42

2,56

2,49
Quantidade de água: $118 \mathrm{ml}$ (fator a/c 0,295)

Tempo de início de pega: 02h40min.

Tempo de fim de pega: 04h30min. 


\section{TABELA 7: Resistência à compressão da argamassa.}

\section{Resistência à compressão \\ Índice de consistência da argamassa}

3 dias de idade

7 dias de idade

28 dias de idade

\begin{tabular}{|c|c|c|c|c|c|c|}
\hline №. $\mathrm{CP}$ & $\begin{array}{l}\text { Carga de } \\
\text { ruptura } \\
\text { (kgf) }\end{array}$ & $\begin{array}{c}\text { Resistência à } \\
\text { compressão } \\
\text { (MPa) }\end{array}$ & $\begin{array}{c}\text { Carga de } \\
\text { ruptura } \\
\text { (kgf) }\end{array}$ & $\begin{array}{l}\text { Resistência à } \\
\text { compressão } \\
(\mathrm{MPa})\end{array}$ & $\begin{array}{l}\text { Carga de } \\
\text { ruptura (kgf) }\end{array}$ & $\begin{array}{c}\text { Resistência à } \\
\text { compressão (MPa) }\end{array}$ \\
\hline 1,00 & $4.660,57$ & 23,30 & $6.430,27$ & 32,10 & $8.309,88$ & 41,50 \\
\hline 2,00 & $6.342,33$ & 31,70 & $7.232,67$ & 36,10 & $8.980,39$ & 44,90 \\
\hline 3,00 & $5.869,68$ & 29,30 & $7.243,67$ & 36,20 & $10.717,11$ & 53,50 \\
\hline 4,00 & $5.572,90$ & 27,80 & $7.342,59$ & 36,70 & $9.310,15$ & 46,50 \\
\hline médias & $5.928,30$ & 29,60 & $7.272,98$ & 36,33 & $8.866,81$ & 44,30 \\
\hline Desvio Padrão & \multicolumn{2}{|c|}{3,54} & \multicolumn{2}{|c|}{2,13} & \multicolumn{2}{|r|}{5,05} \\
\hline CV & \multicolumn{2}{|c|}{$11,95 \%$} & \multicolumn{2}{|c|}{$5,87 \%$} & \multicolumn{2}{|r|}{$11,40 \%$} \\
\hline
\end{tabular}

FONTE: Dados obtidos no local.

\section{TABELA 8: Propriedades físicas do RMG.}

\begin{tabular}{lc}
\multicolumn{1}{c}{ Propriedade } & Valor \\
\hline Massa Específica $\left(\mathrm{g} / \mathrm{cm}^{3}\right)$ & 2,66 \\
Forma física & Pó \\
Cor & Cinza \\
Módulo de finura (\%) & 0,237 \\
\hline & FONTE: Dados obtidos no local.
\end{tabular}

Composição

Quant. (\%)

\begin{tabular}{cc}
$\mathrm{SiO} 2$ & 63,785 \\
$\mathrm{Al} 2 \mathrm{O} 3$ & 14,064 \\
$\mathrm{CaO}$ & 6,996 \\
$\mathrm{Fe} 2 \mathrm{O} 3$ & 5,831 \\
$\mathrm{~K} 2 \mathrm{O}$ & 5,248 \\
$\mathrm{MgO}$ & 1,821 \\
$\mathrm{TiO} 2$ & 0,913 \\
$\mathrm{P} 2 \mathrm{O} 5$ & 0,755 \\
$\mathrm{BaO}$ & 0,141 \\
$\mathrm{Ag} 2 \mathrm{O}$ & 0,103 \\
$\mathrm{MnO}$ & 0,08 \\
$\mathrm{ZrO} 2$ & 0,071 \\
$\mathrm{SrO}$ & 0,065 \\
$\mathrm{Eu} 2 \mathrm{O} 3$ & 0,032 \\
$\mathrm{Cl}$ & 0,027 \\
\hline
\end{tabular}


As primeiras informações sobre os possíveis minerais da amostra analisada foram obtidas a partir da descrição de suas propriedades macroscópicas e de informações obtidas nos locais de coleta dos resíduos. Verifica-se na Tabela 10 que os óxidos obtidos e seus percentuais, a presença muito grande de sílica (óxido de silício), aproximadamente $64 \%$, foram comparados com dados de outros estudos o que permite identificar de forma preliminar a amostra como sendo de granito em sua maior composição (NUMMER et al, 2007). A presença de aproximadamente $7 \%$ de óxido de cálcio, nos estudos de Nummer (2007) chegam a 4\%, permite supor a presença de resíduo de mármore, misturados aos de granito, pois o $\mathrm{CaO}$ é um dos componentes principais da composição do mármore. Pode-se notar também o óxido de alumínio $14 \%$ e do óxido de ferro 5,8\%. A não identificação de elementos tóxicos ou radioativos também foi de grande importância para a continuação da pesquisa e a comprovação de que o resíduo utilizado, a saber o RMG de Manaus, tem propriedades de filer inerte, podendo ser adicionado ao concreto sem tratamento pozolânicos, por exemplo, ou cuidados especiais em seu manuseio.

\subsection{PROPRIEDADES REOLÓGICAS}

Neste item são apresentados os resultados dos ensaios dos concretos autoadensáveis no estado fresco e descritos na Tabela 10.

Nos ensaios foi verificada ocorrência de segregação para o CW40, em todos os outros concretos o espalhamento se deu de modo uniforme. As bordas apresentavam-se contendo argamassa e agregados uniformemente misturados indicando que todos possuíam boa coesão. Foi constatado que a maioria dos concretos CS foram classificados segundo a NBR 15823 como sendo concretos classe SF 1 e os concretos CW como SF 2, ou seja, adequados para a maioria das aplicações correntes - paredes, vigas, pilares e outras. A classe SF 1 é um concreto autoadensável bombeado, adequados para estruturas não armadas ou com baixa taxa de armadura e embutidos, cuja concretagem é realizada a partir do ponto mais alto co deslocamento livre - lajes. Os concretos de classe SF 3 tem aplicação em estrutura com alta taxa de armadura e/ou de forma arquitetônica complexa, com o uso de concreto com agregado graúdo de pequenas dimensões (menor que $12,5 \mathrm{~mm}$ ).

Tabela 10: Valores obtidos nos ensaios do CAA no estado fresco.

\begin{tabular}{|c|c|c|c|c|c|c|c|c|c|c|c|c|}
\hline \multirow{2}{*}{$\begin{array}{c}\text { Mistura } \\
\text { (\%) }\end{array}$} & \multirow{2}{*}{$\begin{array}{c}\begin{array}{c}\text { Abatimento } \\
(\mathrm{mm})\end{array} \\
\\
(\mathrm{mm})\end{array}$} & \multicolumn{2}{|c|}{$\begin{array}{r}\begin{array}{c}\text { Espalhamento } \\
\text { do tronco de } \\
\text { cone }(\mathrm{mm})\end{array} \\
\text { Classe - }\end{array}$} & \multicolumn{2}{|c|}{$\begin{array}{c}\text { Espalhamento } \\
\text { T500mm }\end{array}$} & \multicolumn{3}{|c|}{ Funil "V” } & \multicolumn{4}{|c|}{ Caixa "L” } \\
\hline & & $\begin{array}{l}\text { média } \\
\text { (mm) }\end{array}$ & $\begin{array}{c}\text { Classe - } \\
\text { NBR } \\
15823\end{array}$ & $\begin{array}{c}\text { Tempo } \\
\text { (s) }\end{array}$ & $\begin{array}{c}\text { Classe - } \\
\text { NBR } \\
15823\end{array}$ & $\begin{array}{c}1 \\
\min \\
(s)\end{array}$ & $\begin{array}{c}5 \\
\min \\
(s)\end{array}$ & $\begin{array}{c}\text { Classe - } \\
\text { NBR } \\
15823\end{array}$ & H2/H1 & $\begin{array}{c}\text { T } 40 \\
\text { (s) }\end{array}$ & $\begin{array}{c}\text { T20 } \\
\text { (s) }\end{array}$ & $\begin{array}{c}\text { Classe - } \\
\text { NBR } \\
15823\end{array}$ \\
\hline CSO & 275 & 750 & SF 2 & 4,5 & VS 2 & 20,8 & 24,4 & VF 2 & 0,89 & 1,48 & $<1,0$ & PJ 2 \\
\hline CS10 & 260 & 650 & SF 1 & 2,0 & VS 1 & 7,9 & 9,8 & VF 1 & 0,86 & 3,19 & $<1,0$ & PJ 2 \\
\hline CS15 & 275 & 645 & SF 1 & 1,7 & VS 1 & 5,4 & 8,3 & VF 1 & 0,89 & 2,7 & $<1,0$ & PJ 2 \\
\hline CS20 & 275 & 740 & SF 2 & 1,4 & VS 1 & 4,9 & 6,9 & VF 1 & 0,92 & 1,9 & $<1,0$ & PJ 2 \\
\hline cWo & 275 & 745 & SF 2 & 8,7 & VS 2 & 48,9 & 34,6 & NA & 0,67 & 10,8 & 4,7 & NA \\
\hline CW5 & 260 & 650 & SF 1 & 6,4 & VS 2 & 8,8 & 10,3 & VF 2 & 0,80 & 4,22 & 4,3 & PJ 2 \\
\hline CW10 & 275 & 855 & SF 3 & 4,6 & VS 2 & 19,2 & 22,3 & VF 2 & 0,82 & 1,8 & $<1,0$ & PJ 2 \\
\hline CW20 & 270 & 740 & SF 2 & 4,2 & VS 2 & 21,4 & 23,1 & VF 2 & 0,85 & 5,1 & 1,7 & PJ 2 \\
\hline CW30 & 270 & 742,5 & SF 2 & 3,9 & VS 2 & 22,5 & 24,8 & VF 2 & 0,82 & 5,6 & 1,9 & PJ 2 \\
\hline CW40 & 255 & 765 & SF 3 & 5,3 & VS 2 & 26,7 & 35,4 & NA & 0,49 & 22,4 & 4,7 & NA \\
\hline
\end{tabular}


classificados como sendo de classe VF 2, que segundo a NBR 15823 são concretos que adequados para a maioria das aplicações correntes, mas podem acumular uma quantidade de ar aprisionado e isso afeta negativamente na superfície de acabamento e no preenchimento dos cantos das fôrmas, mas os indica para vigas e pilares.

$O$ valor do quociente entre essas duas alturas, $\mathrm{H} 2 / \mathrm{H} 1$, classificam em que situações o CAA pode ser utilizado, de acordo com a NBR 15823 (ABNT, 2010). Pela norma esse quociente deve ser maior ou igual 0,80 . Todos os concretos, exceto os CWO e CW40, foram classificados como PJ 2, segundo a norma, ou seja, são concretos adequados para a maioria das aplicações correntes, tais como elementos estruturais com espaçamentos de armadura de 60 a $80 \mathrm{~mm}$, vigas, pilares, tirantes, indústria de pré-moldados.

\subsection{PROPRIEDADES MECÂNICAS}

As Tabelas 11 e 12 apresentam os resultados de resistência à compressão, respectivamente para CAA com superplastificante Sikament e os CAA com superplastificante Powerflow, bem como os desvios padrão e coeficiente de variação dessas resistências.

\begin{tabular}{ccccccccccc}
\hline \multicolumn{2}{|c}{ TABELA 11: Resistência à compressão dos corpos de provas, desvio padrão e coeficiente de variação - } \\
CAA com Sika.
\end{tabular}

FONTE: Dados obtidos no local.

TABELA 12: Resistência à compressão dos corpos de provas, desvio padrão e coeficiente de variação - CAA com Power Flow.

\begin{tabular}{cccccccccc} 
Idade & MÉDIA & $\begin{array}{c}\text { 7 DIAS } \\
\text { Desvio } \\
\text { padrão }\end{array}$ & CV & MÉDIA & $\begin{array}{c}\text { 28 DIAS } \\
\text { Desvio } \\
\text { padrão }\end{array}$ & CV & MÉDIA & $\begin{array}{c}\text { 90 DIAS } \\
\text { Desvio } \\
\text { padrão }\end{array}$ & CV \\
\hline CW0 & 37,85 & 1,2 & $3,18 \%$ & 45,6 & 3,54 & $7,75 \%$ & 51,75 & 4,45 & $8,61 \%$ \\
CW5 & 37,5 & 1,41 & $3,77 \%$ & 43,25 & 0,64 & $1,47 \%$ & 46,85 & 1,2 & $2,57 \%$ \\
CW10 & 36,8 & 0,14 & $0,38 \%$ & 46,05 & 3,75 & $8,14 \%$ & 48,85 & 0,07 & $0,14 \%$ \\
CW20 & 33,35 & 0,21 & $0,64 \%$ & 43,25 & 0,64 & $1,47 \%$ & 47,25 & 4,45 & $9,43 \%$ \\
CW30 & 32,2 & 0,99 & $3,07 \%$ & 39,35 & 1,2 & $3,05 \%$ & 43,15 & 1,48 & $3,44 \%$ \\
CW40 & 20,3 & 0,99 & $4,88 \%$ & 21,8 & 1,84 & $8,43 \%$ & 24,6 & 0,71 & $2,87 \%$ \\
\hline
\end{tabular}

FONTE: Dados obtidos no local. 
provas totalmente endurecido somente no terceiro dia após a moldagem nas formas metálicas e por isso não foram rompidos corpos de prova na idade de 7 dias.

Para os concretos CW o supracitado não ocorreu, sendo os corpos de prova normalmente colocados em cura úmida 24 horas após a mistura na betoneira e deixado até a data de rompimento na prensa para determinação da resistência à compressão. Foram substituídas porcentagens de cimento por resíduos RMG até o limite de $40 \%$. Isto se deu devido fato de os concretos nesse percentual não apresentarem propriedades de CAA.

Verificou-se que os concretos $\mathrm{CW}$ alcançaram maiores valores de resistência à compressão para o mesmo porcentual de substituição do cimento por RMG quando comparado com os concretos da classe CS. Observou-se que os concretos da classe CW apresentaram evolução progressiva desses valores em comparação com a evolução dos valores de resistência dos concretos CS correspondentes, exemplo o CW0 teve sua resistência inicial de 37,9 MPa e aos 90 dias de 51,8 , o que corresponde a um aumento de $37 \%$ aproximadamente. Para concreto CSO esse aumento foi de pouco mais de $4 \%$, tendo sua resistência inicial $35,4 \mathrm{MPa}$ até $36,9 \mathrm{MPa}$ aos 90 dias.

Os valores de resistências à flexão são apresentadas na Tabela 13. Pode-se observar que todas as placas satisfazem à limite estabelecido na NBR 15805 (ABNT, 2010) que exige que a ruptura mínima deve ocorrer a 4,5 MPa. Apesar de se obter valor médio de resistência à flexão para placas contendo $40 \%$ de substituição de cimento por resíduo, esse concreto não apresentou resultado que o classificassem como CAA nos ensaios de propriedades reológicas, chegando até o ponto de ocorrer segregação em alguns casos.

\section{TABELA 13: Resistência á flexão. Tensões e cargas obtidas nos ensaios de flexão de placas de CAA.}

\begin{tabular}{ccccccc} 
RMG & \multicolumn{6}{c}{ Resistência à Flexão nas placas de CAA (MPa). } \\
& CP1 & CP2 & CP3 & Média & $\begin{array}{l}\text { Desvio } \\
\text { Padrão }\end{array}$ & CV \\
\hline $\mathbf{0 \%}$ & 7,75 & 8,22 & 8,55 & 8,17 & 0,40 & $4,92 \%$ \\
$\mathbf{2 0 \%}$ & 7,89 & 8,11 & 6,77 & 7,59 & 0,72 & $9,47 \%$ \\
$\mathbf{3 0 \%}$ & 7,60 & 7,50 & 7,00 & 7,37 & 0,32 & $4,36 \%$ \\
$\mathbf{4 0 \%}$ & 7,48 & 6,71 & 6,76 & 6,98 & 0,43 & $6,17 \%$ \\
\hline
\end{tabular}

FONTE: Dados obtidos no local.

\subsection{PROPRIEDADES FÍSICAS E QUÍMICAS}

Essas propriedades foram obtidas seguindo os critérios adotados pela norma ABNT NBR 9778:2005 (ABNT, 2009). Os valores obtidos nos ensaios com corpos de prova de CAA para determinação de absorção, índice de vazios e massa específica estão registrados na Tabela 14.

Os valores de absorção e de índice de vazios, calculados nesses corpos de provas, ficaram próximos de $5 \%$ para absorção e menores que $10 \%$ para índice de vazios. Isso é uma indicação de que os esse tipo de concreto possui permeabilidade muito baixa, ou seja, são concretos que se utilizados para formar estruturas dificilmente apresentarão falhas de concretagem devido a adensamento incompleto e exsudação, e consequente redução de resistência, os riscos com problemas futuros de carbonatação e oxidação das armaduras estará consideravelmente reduzido.

Os valores de expansão das barras de argamassas para se medir a RAA são apresentados resumidamente na Tabela 15. 
TABELA 15: Deformação das barras de argamassas e de concreto imersas em solução alcalina.

Comprimento das barras em mm e percentual de expansão.

\begin{tabular}{|c|c|c|c|c|c|c|c|c|}
\hline \% RMG & Dia 01 & $\%$ & Dia 03 & $\%$ & Dia 7 & $\%$ & Dia 14 & $\%$ \\
\hline \multirow{4}{*}{$0 \%$} & 285,68 & 0 & 285,76 & 0,03 & 285,96 & 0,10 & 285,88 & 0,07 \\
\hline & 285,8 & 0 & 285,96 & 0,06 & 286,02 & 0,08 & 285,96 & 0,06 \\
\hline & 285,86 & 0 & 285,82 & $-0,01$ & 285,92 & 0,02 & 286,06 & 0,07 \\
\hline & 285,98 & 0 & 285,9 & $-0,03$ & 285,96 & $-0,01$ & 285,8 & $-0,06$ \\
\hline \multirow{4}{*}{$20 \%$} & 285,78 & 0 & 285,75 & $-0,01$ & 286,04 & 0,09 & 286,04 & 0,09 \\
\hline & 285,94 & 0 & 286 & 0,02 & 286 & 0,02 & 285,88 & $-0,02$ \\
\hline & 286,42 & 0 & 286,36 & $-0,02$ & 286,38 & $-0,01$ & 286,38 & $-0,01$ \\
\hline & 286,5 & 0 & 286,47 & $-0,01$ & 286,48 & $-0,01$ & 286,48 & $-0,01$ \\
\hline \multirow{4}{*}{$30 \%$} & 286,32 & 0 & 286,42 & 0,03 & 286,38 & 0,02 & 286,48 & 0,06 \\
\hline & 286,48 & 0 & 286,5 & 0,01 & 286,48 & 0,00 & 286,52 & 0,01 \\
\hline & 286,42 & 0 & 286,44 & 0,01 & 286,48 & 0,02 & 286,5 & 0,03 \\
\hline & 286,52 & 0 & 286,52 & 0,00 & 286,5 & $-0,01$ & 286,52 & 0,00 \\
\hline \multirow{4}{*}{$40 \%$} & 285,84 & 0 & 285,94 & 0,03 & 285,88 & 0,01 & 285,88 & 0,01 \\
\hline & 286,38 & 0 & 286,48 & 0,03 & 286,4 & 0,01 & 286,48 & 0,03 \\
\hline & 286,21 & 0 & 286,22 & 0,00 & 286,18 & $-0,01$ & 286,36 & 0,05 \\
\hline & 286,28 & 0 & 286,34 & 0,02 & 286,32 & 0,01 & 286,4 & 0,04 \\
\hline
\end{tabular}

FONTE: Dados obtidos no local.

Verifica-se que todos os valores obtidos ficaram abaixo de $0,10 \%$, em todos os dias, o que de acordo com a norma brasileira NBR 15577 esse material pode ser considerado como inócuo, ou seja, pode ser utilizado no concreto sem tratamento químico, pois fica evidenciado que não ocorrerá formação de gel expansivo responsável por patologias de fissuras superficiais e internas nas estruturas de concreto.

\section{CONCLUSÕES}

O traço adotado na produção dos concretos desta pesquisa, com o consumo de cimento de $526 \mathrm{~kg} / \mathrm{m}^{3}$, possui as seguintes proporções de materiais componentes em massa: 1,000 (cimento + RMG) : 1,15 (areia) : 1,80 (brita) : 0,41 (água). Fica recomendado, de acordo com a NBR 15823 (ABNT, 2010) como adequado para utilização na maioria das aplicações correntes, inclusive para elementos estruturais de alta densidade de armadura e de pré-moldados, uma vez que o mesmo obteve resultados satisfatórios na produção de CAA, assim como o cimento CP I-S-32 -
Amazon Cemex, embalado no polo industrial de Manaus, utilizado nessas pesquisa.

Os resultados mostraram-se eficazes no que se refere à substituição de cimento Portland por RMG provenientes das empresas de corte e acabamentos de rochas ornamentais, secos e de diâmetros menores que $75 \mu \mathrm{m}$ (passantes na peneira \# 200) em substituição ao cimento nas seguintes proporções: até $30 \%$ sobre a massa de cimento quando o superplastificante utilizado for o Powerflow 1159 da empresa MC-Bauchemie do Brasil na dosagem de $1,0 \%$ sobre a massa do cimento; e ; até $20 \%$ sobre a massa de cimento quando o superplastificante utilizado for o Sikament 251 fabricado pela empresa SIKA S.A. na dosagem de $1,0 \%$ sobre a massa do cimento. Isso foi observado pois alcançou-se bons resultados na análise dos valores obtidos nos ensaios no estado fresco, em que de acordo com a norma vigente ficou em uma excelente classificação, todas de concreto adequado para utilização na maioria das aplicações correntes, inclusive para elementos estruturais de alta densidade de armadura e de pré-moldados. Os traços CS10, CS15, CS20, CW5, CW10, CW20 e CW30 
foram considerados como CAA. Os traços CS10, CS15 e CW5 foram considerados como CAA, com fluidez SF 1 e os traços CS20, CW10, CW20 e CW30 com fluidez SF 2. Todos com viscosidade plástica entre VS 1 e VS2.

Observou-se boa evolução da resistência à compressão axial nas idades de 7, 28 e 90 dias, para os concretos CW, e nas idades de 14, 28 e 90 dias, para os concretos CS, em função das características do RMG servirem como pontos de nucleação para os produtos de hidratação e a alteração da microestrutura da zona de transição do cimento Portland comum com adições CP II-S-32 - Amazon Cemex, empregado nesta pesquisa. Os traços CS15, CS20, CW5, CW10, CW20 e CW30 alcançaram valores de resistência a compressão muito próximos dos valores de resistência à compressão do concreto de referência, CSO e CWO, cujo valor ultrapassou o valor teórico calculado por ocasião da determinação da dosagem. Isso os posiciona como concretos alternativos de serem utilizados para a produção de elementos estruturais. Na definição teórica da dosagem o fck calculado foi de $35 \mathrm{MPa}$ e para CS20 obteve-se resistência de $33 \mathrm{MPa}, 5,7 \%$ menor. Para a mistura CW5, 46, 9 Mpa aos 28 dias, ou seja, 34\% maior que o valor calculado; para a mistura com $10 \%$ de substituição aos 28 dias, o CW10, alcançouse resistência à compressão de $46 \mathrm{MPa}$, ou seja, $31,43 \%$ maior do que o calculado. Para os CW20 e CW30, os valores alcançados aos 28 dias, de 43,3 $\mathrm{MPa}$ e de 39,4 $\mathrm{MPa}$, respectivamente, mostraram a eficácia dessas misturas.

A resistência à flexão alcançada na idade de 90 dias mostrou-se satisfatória e atendeu aos requisitos da norma brasileira que exige valor mínimo de 4,5MPa, para placas de pisos e pavimentos de concreto. Os traços CW20 e CW30 alcançaram valores de 7,59 $\mathrm{MPa}$ e de 7,37 $\mathrm{MPa}$, respectivamente.

Os traços contendo RMG apresentaram maior fluidez que o concreto de referência CSO e CWO. Isso foi demonstrado no ensaio do funil $V$ e da caixa L. Isso se deu possivelmente porque os finos de RMG nessas misturas a tornaram com maior densidade de massa, como pode ser observado nos resultados de massa específica, e consequentemente com menor teor de ar aprisionado, como comprova os ensaios de absorção e de índice de vazios.

Os materiais utilizados na dosagem mostraram-se inócuos no que se refere a reação química prejudicial entre os hidróxidos alcalinos e os elementos químicos que constituem os agregados. Os resultados na análise por fluorescência por raios$X$ não detectaram elementos que prejudicassem as reações químicas ou a saúde dos usuários desses materiais. Os concretos no estado endurecido foram seccionados e observados em microscópio e não foram observadas a formação de géis de expansão na interface argamassa - agregados. As expansões de barras de argamassas e de concretos, quando imersas em solução alcalina, menores que $0,10 \%$ trouxeram uma segurança a mais em se indicar tais materiais como possíveis de serem utilizados nos concretos de estruturas.

\section{REFERÊNCIAS BIBLIOGRÁFICAS}

ASSOCIAÇÃO BRASILEIRA DE NORMAS TÉCNICAS. EB1763: Aditivos para concreto de cimento Portland. Rio de Janeiro, 1992

ASSOCIAÇÃO BRASILEIRA DE NORMAS TÉCNICAS. NBR 6502: Rochas e Solos - Terminologia. Rio de Janeiro, 1995.

ASSOCIAÇÃO BRASILEIRA DE NORMAS TÉCNICAS. NBR 9778: Argamassa e Concreto Endurecidos - Determinação da absorção de água por Imersão - Índice de Vazios e Massa Especifica. Rio de Janeiro, 2005.

ASSOCIAÇÃO BRASILEIRA DE NORMAS TÉCNICAS. NBR 11768: Aditivos para concreto de cimento Portland. Rio de Janeiro, 1990.

ASSOCIAÇÃO BRASILEIRA DE NORMAS TÉCNICAS. NBR 15577-4: Agregados - Reatividade álcali-agregado. Parte 4: Determinação da expansão em barras de argamassa pelo método acelerado. Rio de Janeiro, 2008.

ASSOCIAÇÃO BRASILEIRA DE NORMAS TÉCNICAS. NBR 15805: Placa de concreto para piso - Requisitos e métodos de ensaios - Ed. 2. Rio de Janeiro, 2010.

ASSOCIAÇÃO BRASILEIRA DE NORMAS TÉCNICAS. NBR 15823-1: Concreto autoadensável. Parte 1 Classificação, controle e aceitação no estado fresco. Rio de Janeiro, 2010.

ASSOCIAÇÃO BRASILEIRA DE NORMAS TÉCNICAS. NBR 15823-2: Concreto autoadensável. Parte 2 Determinação do espalhamento e do tempo de 
escoamento. Método do cone de Abrams. Rio de Janeiro, 2010.

ASSOCIAÇÃO BRASILEIRA DE NORMAS TÉCNICAS. NBR 15823-3: Concreto autoadensável. Parte 3 Determinação da habilidade passante - Método do anel J. Rio de Janeiro, 2010.

ASSOCIAÇÃO BRASILEIRA DE NORMAS TÉCNICAS. NBR 15823-4: Concreto autoadensável. Parte 4 Determinação da habilidade passante - Método da caixa L. Rio de Janeiro, 2010.

ASSOCIAÇÃO BRASILEIRA DE NORMAS TÉCNICAS. NBR 15823-5: Concreto autoadensável. Parte 5 Determinação da viscosidade - Método do funil V, Rio de Janeiro, 2010.

ASSOCIAÇÃO BRASILEIRA DE NORMAS TÉCNICAS. NBR 15823-6: Concreto autoadensável. Parte 6 Determinação da resistência à segregação - Método da coluna de segregação. Rio de Janeiro, 2010.

ANDRADE, Carlos Eduardo Silva. Análise e caracterização de cinzas do processo de incineração de resíduos de serviço de saúde para reaproveitamento. Belo Horizonte: Universidade Federal de Minas Gerais, 2012.

BARBOSA, M. T. Estudo Sobre a Areia Artificial em Substituição à Natural para Confecção de Concreto. Juiz de Fora: Departamento de Construção Civil Universidade Federal de Juiz de Fora Campus Universitário. Bairro Martelos, 2008.

BARROS, P. G. Avaliação das Propriedades de Durabilidade do Concreto Autoadensável Obtido com Resíduo de Corte de Mármore e Granito. Maceió: Universidade Federal de Alagoas, 2008.

BARROS FILHO, R. M. Rochas: Mármores e Granitos. Basalto e Gabro. Belo Horizonte: Faculdade INAP, 2005.

BARTHOLOMEI, M. B. Estudo de Concreto AutoAdensável com a Utilização de Materiais da Região de Manaus e Resíduo de Vidro como Modificador de Viscosidade. Faculdade de Tecnologia da Universidade Federal do Amazonas - FT/UFAM. Manaus - AM. 2013.

BAPTISTA, Allan Silveira. et al. Avaliação da reação álcaliagregado da areia natural da região metropolitana de Porto Alegre, Brasil e do uso de sílica ativa. Porto Alegre: Universidade Federal do Rio Grande do Sul, 2013.

BERTOCINI, Sandra R. et al. Estudo de caso: Adequação de traço de CAA com uso de areia de britagem na indústria de pré-fabricado. São Carlos: $3^{\circ}$ Encontro Nacional de Pesquisa-Projeto-Produção em Concreto Pré Moldado da UFSCar, 2013.

CHIODI FILHO, Cid, RODRIGUES. E. de P. Guia de Aplicação de Rochas em Revestimentos. Projeto Bula.
São Paulo: Abirochas, 2009.

CORREIA GOMES, P. C. C. e BARROS, A. R de. Métodos de dosagem de concreto autoadensável. São Paulo: Editora PINI, 2009.

FRASCÁ, M. H. B. de O. Caracterização Tecnológica de Rochas Ornamentais e de Revestimento: Estudo por Meio de Ensaios e Análises e das Patologias Associadas ao Uso. Recife: III Simpósio sobre Rochas Ornamentais do Nordeste, 2002.

GONÇALVES, J. P. Utilização do Resíduo de Corte de Granito (RCG) como Adição para Produção de Concretos. Porto Alegre - RS: Escola de Engenharia de Rio Grande do Sul. 2002.

LARIZZATTI, R. G. e MENESES. R. G de. Rochas Ornamentais e de Revestimento: Conceitos, Tipos e Caracterização Tecnológica. Curso De Especialização Em Mármores E Granitos. Rio de Janeiro: Departamento de Geologia da Universidade Federal do Rio de Janeiro, 2005.

LISBÔA, E. M.. Obtenção do Concreto Autoadensável Utilizando Resíduo do Beneficiamento do Mármore e Granito e Estudo de Propriedades Mecânicas. Maceió: Universidade Federal De Alagoas, 2004.

LOPES, J. L. Estudo do Potencial de Utilização do Resíduo de Beneficiamento de Mármore e Granito (RBMG), como Fíler, na Produção de Concretos. Goiânia: Programa de Pós-Graduação em Engenharia do Meio Ambiente da UFG, 2006.

LÓPEZ. D. A. R, et al. Avaliação das propriedades físicas e mecânicas de concretos produzidos com vidro cominuído como agregado fino. Santa Cruz do Sul: Dissertação de mestrado, Universidade de Santa Cruz do Sul, 2005.

MARANGON, E. Caracterização Material e Estrutural de Concretos. Rio de Janeiro: Dissertação de mestrado, Universidade Federal do Rio de Janeiro, 2011.

MARÇAL, R. L. Fabricação de Vidros Especiais a Partir de Resíduos da Indústria de Rochas Ornamentais. Rio De Janeiro, Dissertação de mestrado, Instituto Militar de Engenharia, 2011.

MARQUES, A. C. Concreto Autoadensável: Caracterização da Evolução das Propriedades Mecânicas e Estudo da Sua Deformabilidade por Solicitação Mecânica. Retração e Fluência. São Paulo: Tese de Doutorado, Escola Politécnica da Universidade de São Paulo. Programa de Pós-Graduação em Engenharia Civil, 2011.

MIRANDA, R. A. C. Estudo da Aplicação de Resíduo de Beneficiamento de Mármore e Granito em Tijolos de Solo-Cimento. Goiânia: Dissertação de mestrado, Escola de Engenharia Civil - Universidade Federal de Goiás, 
2012.

MOLINARI, É. J. Reutilização dos Resíduos de Rochas Naturais Para o Desenvolvimento de Compósitos Polímericos com Matriz Termofixa na Manufatura de Pedras Industriais. Universidade Federal de Santa Catarina. Florianópolis - SC. 2007.

PADILHA DOS SANTOS. A. Estudo Experimental e Análise da Viabilidade do Emprego do Pó de Mármore Para a Produção de Concreto Autoadensável. Curitiba: Dissertação de mestrado, Universidade Tecnológica Federal do Paraná- Campus Curitiba - Departamento Acadêmico de Construção Civil - Tecnologia em Concreto, 2012.

PAUMGARTTEN, M. D. Concreto Autoadensável com Materiais Encontrados na Região de Belém. Belém: Dissertação de mestrado, Universidade da Amazônia UNAMA, 2010.

RANIA A. Hamza. Marble and Granite Waste: Characterization and Utilization in Concrete Bricks. Environmental Engineering Program in the American University in Cairo. Cairo - Egito. 2011.

ROMANO. C. A. Apostila de Tecnologia do Concreto. Curitiba: Centro Federal de educação Tecnológica do Paraná, 2004.

SATO. N. M. N. Análise da Porosidade e de Propriedades de Transporte de Massa em Concretos. São Paulo: Universidade de São Paulo, 1998.

SANTOS, R. A. Reaproveitamento dos Residuos de Britagem de Granito. Universidade Federal da Paraíba. João Pessoa - PB. 2011.

STEFENON, F. Incorporação de Resíduos Industriais em Concreto Betuminoso Usinado à Quente. Universidade Federal do Rio Grande do Sul. Porto Alegre - RS. 2003.

SEBRAE - Serviço Brasileiro de Apoio à Micro e Pequena Empresa. Boletim: Construção Civil: Marmorarias. Vitória: 2014.

SOUSA FILHO, L. M. Concreto Autoadensável e de Alto Desempenho Produzido com Fibras de Polipropileno e Materiais Disponíveis na Região Metropolitana de Manaus. Manaus: Faculdade de Tecnologia da Universidade Federal do Amazonas, 2011.

TUTIKIAN, B. F. e DAL MOLIN. Concreto Autoadensável. São Paulo: Editora PINI Ltda., 2008. 